\section{Monitoring response patterns of individual monkeys living in groups}

ROBERT H. ELTON and ANTHONY R. KJELDSEN
Eastern Washington State College, Cheney, washington 99004

There are occasions experimentally when the researcher working with groups of animals needs to know which animal is responding, the duration of the response, and the time at which it occurs. Generally, the experimenter requires good reliability with the least amount of interference to the animals and their environment.

There are, of course, several methods that might be used. For example, Cadell, Cressman, Parsons, and Hills (1972) used a telemetry technique to identify subjects in a study with similar requirements. A radio transmitter was attached to a harness on the back of each animal. Using tuned reed relays, they were able to identify individual monkeys that made contact with a metal target object.

For our purposes, problems associated with radio telemetry (i.e., interference, expense, subject manipulation of apparatus, etc.) were difficult to surmount. So we used a simple camera technique to identify individual animals in a group making a particular response during 24-h intervals.

Our research required that monkeys be allowed to control the dispensing of an alcohol solution (the independent variable of interest). The alcohol solution was available to the animals through a single stainless steel drinking spout which protruded $2.54 \mathrm{~cm}$ through a clear Plexiglas window into a room containing a group of unrestricted monkeys. A microswitch attached to the drinking spout activated three events when pressed downward by an animal: (1) $2.5 \mathrm{ml}$ of solution was dispensed, (2) a single-frame picture of the monkey drinking was taken by a Super 8 movie camera with a solid state single-frame switch $^{1}$, and (3) the event

This study was supported by a grant from the Distilled Spirits Council of the United States, National Institutes of Health Grant RR00166 to the Regional Primate Research Center at the University of Washington, and a grant from the Primate Research Program, Eastern Washington State College. A copy of the paper describing use of this technique in an experimental situation with monkeys may be obtained by writing the senior author, c/o Department of Psychology, Eastern Washington State College, Cheney, Washington 99004. was recorded on a printout counter. A 2-sec delay was programmed into the system, so that an animal was unable to repeatedly trigger the microswitch and obtain a constant flow of solution.

A BRS programmable printout counter was used to record the day of the experiment, 24-h total responses, the hour of the experiment, and hourly total responses. (Of course, other printout counters can be used.) This information was printed onto a tape every hour, and the counter was reset. An electric clock controlled the hourly operation of the counter, and simultaneously turned off a spotlight, triggering the camera and expos. ing one frame of film. If there were any doubts about the operation of the camera, the frames taken in an hour were checked against the printout counter's hourly total. The camera was set to a single-frame operation mode, placed $2.1 \mathrm{~m}$ from the Plexiglas window, and controlled by the BRS/LVE solid state control rack. Using the zoom lens, only a picture of the monkey's head was taken. Individual animals can be tatooed (e.g., on the left supraorbital ridge on monkeys) with different binary codes to insure reliable identification. A $100-W$ light bulb was constantly directed at the window to provide illumination.

In our study, Kodak Type G film No. 287938 rated at ASA 160 was used. Animals were identified by reviewing the film through a Super 8 film editor. Three thousand single frames of information are obtained from one cassette. An experienced technician can retrieve the data from a cassette in $90 \mathrm{~min}$.

A computer program for analyzing high blood alcohol levels for animals in a group situation is described by Scott and Wilson (1976).

\section{REFERENCES}

Cadell, T. E., Cressman, R. J., Parsons, D. L., \& Hills, A. H. A contact detection system for identifying individual animals in groups. Physiological Behavior, 1972, 9. 667-669.

Scotr, M. W., \& Wilson, M. E. Predicting high blood alcohol levels for animals in a group situation. Behavior Research Methods \& Instrumentation, 1976, in press.

\section{NOTE}

1. The basic idea of using the camera in this manner was suggested by the late Albert Johnson, Moscow, Idaho. 